ATOMIC DYNAMICS IN LIQUIDS 


\title{
ATOMIC DYNAMICS IN LIQUIDS
}

\author{
N. H. MARCH, \\ Professor of Physics, Imperial College of Science and Technology, London, U.K. \\ and
}

M. P. TOSI,

Professor of Physics, University of Rome, Italy

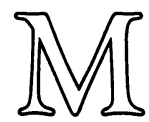


(C) N. H. March and M. P. Tosi 1976

Softcover reprint of the hardcover 1st edition 1976

All rights reserved. No part of this publication may be reproduced or transmitted, in any form or by any means, without permission

This book is sold subject to the standard conditions of the Net Book Agreement

First published 1976 by

THE MACMILLAN PRESS LTD.

London and Basingstoke

Associated companies in New York Dublin

Melbourne Johannesburg and Madras

ISBN 978-1-349-00931-2 ISBN 978-1-349-00929-9 (eBook)

DOI 10.1007/978-1-349-00929-9

Filmset in Ireland by Doyle Photosetting Ltd., Tullamore 


\section{CONTENTS}

Preface vi

1 Static Structure and Thermodynamics 1

2 Calculation of Liquid Structure from a Law of Force 8

3 Liquid Dynamics and Time-dependent Correlation Functions 35

4 Hydrodynamic Forms of Correlation Functions and Generalised Hydrodynamics 55

5 Microscopic Theories of the van Hove Function 78

6 Structure and Dynamics of Binary Fluids 101

7 Charged Fluids 136

8 Helium Liquids 196

9 Critical Phenomena 233

10 The Liquid Surface 256

$\begin{array}{ll}\text { Appendices } & 279\end{array}$

References $\quad 315$

Index 325 


\section{Preface}

This book presents the subject of dynamics of atoms in liquids in a form which should be useful for established research workers in the field of the physics and chemistry of the liquid state. It should also be useful to research students entering this field but, of course, quite a bit of background will then be necessary for an understanding of this work. Specifically, we have assumed that the reader will have successfully completed a basic course on statistical mechanics and thermodynamics and, since the book deals with quantal as well as classical fluids, a basic course in quantum mechanics. However, only in the advanced part of Chapter 9 on Critical Phenomena is detailed knowledge of quantum field theory assumed.

Some of the material in this book has formed the basis of advanced level courses given by the authors. One of us in particular (M.P.T.) has drawn upon it for lectures given at the University of Rome and at the Postgraduate School at L'Aquila, organised by the Consiglio Nationale delle Ricerche for condensed matter physicists. Supplemented by some material from Landau and Lifshitz's Statistical Physics, courses of from 10 to 20 lectures to first and second year postgraduate students have been given at different times on portions of this book.

There are several points relating to the presentation which need brief comment. First, though we have called the work Atomic Dynamics in Liquids, some attention is also paid to the dynamics of electrons in Chapter 7. Secondly, we have thought it helpful to include, albeit in rather elementary terms, an account of the recent progress in the understanding of liquid helium three, and of critical phenomena. We are conscious that neither of us has contributed to these fields and that great use has been made of the presentation developed by other workers (particularly A. J. Leggett on helium three, who of course is in no way responsible for any of our final presentation here).

Though we felt it important to include a final chapter on the liquid surface, this is now a subject for a book in its own right and we are aware that the choice of material is idiosyncratic. Fortunately, in C. A. Croxton's book The Liquid State, there is a useful source for readers who wish to take this field somewhat further.

Many colleagues have influenced our thinking in this area over the past decade. To them, and to all authors and publishers who have given us permis- 
sion to include figures and tabular material from the original sources, we are most grateful.

Finally, we shall be grateful if readers who find the book useful would write to tell us where we might make improvements in the future. It is too much to hope that a work on this scale, and of such a degree of complexity, could be completely free from error.

London and Rome, 1976

N. H. M.

M. P. T. 